\title{
EVALUATING HUMIDITY RECOVERY EFFICIENCY OF CURRENTLY AVAILABLE HEAT AND MOISTURE EXCHANGERS: A RESPIRATORY SYSTEM MODEL STUDY
}

\author{
Jeanette Janaina Jaber Lucato, ${ }^{\mathrm{I}, \mathrm{II}, \mathrm{III}}$ Alexander Bernard Adams, ${ }^{\mathrm{IV}}$ Rogério Souza, ${ }^{\mathrm{I}}$

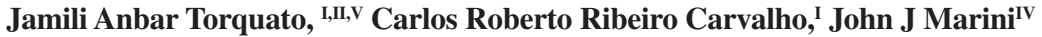

doi: 10.1590/S1807-59322009000600015

Lucato JJJ, Adams AB, Souza R, Torquato JA, Carvalho CRR, Marini JJ. Evaluating humidity recovery efficiency of currently available heat and moisture exchangers: a respiratory system model study. Clinics. 2009;64(6):585-90.

OBJECTIVES: To evaluate and compare the efficiency of humidification in available heat and moisture exchanger models under conditions of varying tidal volume, respiratory rate, and flow rate.

INTRODUCTION: Inspired gases are routinely preconditioned by heat and moisture exchangers to provide a heat and water content similar to that provided normally by the nose and upper airways. The absolute humidity of air retrieved from and returned to the ventilated patient is an important measurable outcome of the heat and moisture exchangers' humidifying performance.

METHODS: Eight different heat and moisture exchangers were studied using a respiratory system analog. The system included a heated chamber (acrylic glass, maintained at $37^{\circ} \mathrm{C}$ ), a preserved swine lung, a hygrometer, circuitry and a ventilator. Humidity and temperature levels were measured using eight distinct interposed heat and moisture exchangers given different tidal volumes, respiratory frequencies and flow-rate conditions. Recovery of absolute humidity (\%RAH) was calculated for each setting.

RESULTS: Increasing tidal volumes led to a reduction in \%RAH for all heat and moisture exchangers while no significant effect was demonstrated in the context of varying respiratory rate or inspiratory flow.

CONCLUSIONS: Our data indicate that heat and moisture exchangers are more efficient when used with low tidal volume ventilation. The roles of flow and respiratory rate were of lesser importance, suggesting that their adjustment has a less significant effect on the performance of heat and moisture exchangers.

KEYWORDS: Heat and moisture exchangers; Humidity; Temperature; Mechanical ventilation.

\section{INTRODUCTION}

The goal of artificially preconditioning inspired gases delivered to ventilated, intubated patients is to provide a heat and water content at the level of the carina that is similar to that usually provided by the nose and upper

\footnotetext{
${ }^{\text {I }}$ Pulmonary Division, Respiratory ICU, Hospital das Clinicas da Faculdade de Medicina da Universidade de São Paulo - São Paulo/SP, Brazil.

"Physical Therapy Facility, Hospital das Clinicas da Faculdade de Medicina da Universidade de São Paulo - São Paulo/SP, Brazil.

III Centro Universitário São Camilo - São Paulo/SP, Brazil.

Iv Regions Hospital, St. Paul - Minnesota, USA.

${ }^{v}$ Universidade Cruzeiro do Sul - São Paulo/SP, Brazil.

Email: jeanettejaber@yahoo.com

Tel: 5511 3069-6867

Received for publication on February 14, 2009

Accepted for publication on March 10, 2009
}

airways. ${ }^{1}$ Absolute humidity (AH) is the amount of water vapor per unit volume of gas mixture. ${ }^{2}$ When a gas contains its respective total capacity for water vapor for a given temperature, the gas is termed "saturated" (accordingly, AH at saturation is highly dependent on the gas temperature).

Relative humidity $(\mathrm{RH})$ is the ratio of a given $\mathrm{AH}$ relative to the maximal capacity for water vapor of that gas (again, directly dependent on gas temperature). ${ }^{1} \mathrm{~A} \mathrm{RH}$ of less than $100 \%$ represents a humidity deficit or a burden on the airways of the patient. The task of preconditioning to avoid this deficit can be accomplished by heated humidifiers ( $\mathrm{HH}$ or active humidifiers) or by heat and moisture exchangers (HME or passive humidifiers). ${ }^{3-6}$

The $\mathrm{AH}$ of the air retrieved from and returned to the patient is an important indicator of the humidifying performance 
of an HME. ${ }^{7}$ This is important since endotracheal tube/ tracheotomy occlusions may occur when humidity delivery is insufficient. ${ }^{8-11}$

There are three basic types of HME: hygroscopic, hydrophobic and combined (hygroscopic-hydrophobic). ${ }^{12}$ This distinction is important for many reasons; for instance, they lead to distinct effects in terms of ventilatory mechanics. ${ }^{13}$ Hygroscopic HME devices contain materials of low thermal conductivity impregnated with a hygroscopic chemical. Hydrophobic HME units have a larger surface area due to pleating of the material ${ }^{14}$ and feature a substance covering the filter that prevents the water's exodus during exhalation and also serves as an efficient microbiological filter. ${ }^{15,16}$ Combined HME units (hygroscopic-hydrophobic) exhibit humidification performance consistent with the bacterial retention properties of the filter membrane. ${ }^{7,12,17}$ For the combined HME, the hygroscopically-treated material is located between the patient's airway and the filter.

Reports have suggested that increasing the tidal volume, ${ }^{18-23}$ flow rate, ${ }^{18,24}$ or minute ventilation ${ }^{9,18,23}$ will decrease the humidification efficiency of an HME. A consistent measure of humidifying efficiency has not been determined to date for HME use. Testing of humidification efficiency for available HME units under a range of ventilatory conditions has not been reported to date. Therefore, we aimed to evaluate and compare the humidifying efficiency of these adjuncts under conditions of varying tidal volume, respiratory rate, and flow rate.

\section{MATERIALS AND METHODS}

A respiratory system analog (Figure 1) was constructed using preserved swine lungs (BioQuest Inflatable Lungs, NASCO, Ft. Atkinson, WI, USA) in a large plastic box

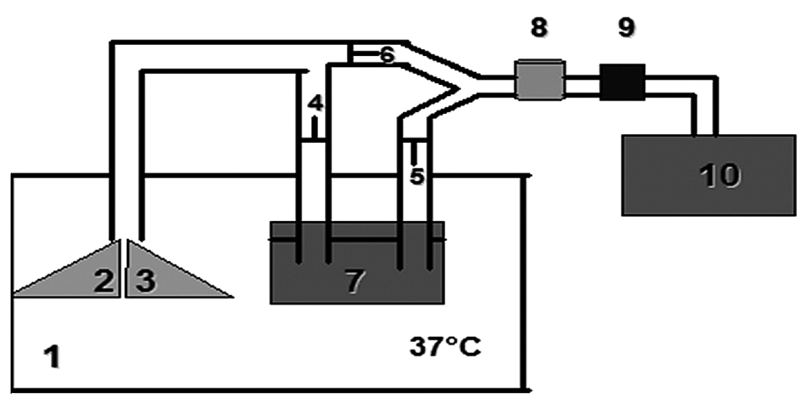

Figure 1 - Mechanical model. Components include: a large plastic box maintained at $37^{\circ} \mathrm{C}(1)$, preserved swine lungs $(2,3)$ and a cascade-type humidifier (7) inside the box. Three unidirectional valves $(4,5$ and 6$)$ were inserted within the tubing section external to the box (representing the airway) to direct flow through the humidifier prior so that it could ventilate the lungs. In this same simulated airway segment, a sensor (Vaisala, HMI 32, Woburn, MA, USA) (8) was positioned to detect AH and temperature. The HME (9) under test was individually installed using a random sequence for each testing period. A mechanical ventilator (10) was used to simulate different ventilatory conditions.

maintained at $37^{\circ} \mathrm{C}$. The lungs were arranged to simulate the bifurcation structure of in vivo lungs. To serve as selfhumidifying lungs, the tubing circuitry was constructed to route airflow through a cascade-type humidifier after which it ventilated the swine lungs (both within the plastic box maintained at $37^{\circ} \mathrm{C}$ using a commercial hot-air dryer).

The system analog was connected to a mechanical ventilator (840, Nellcor Puritan Bennett, Carlsbad, CA, USA) used to simulate ventilatory conditions by varying the tidal volume (VT), respiratory rate (f), and flow rate during volume control mode ventilation (Table 1). Positive endexpiratory pressure (PEEP) was not used.

The testing region featured a section of tubing and connectors external to the box that represented the airways. In this airway segment, eight different HME units were sequentially tested, one of each of the following:

Table 1 - Ventilator settings employed and the corresponding percentage recovery of absolute humidity (\%RAH) for each HME

\begin{tabular}{|c|c|c|c|c|c|c|c|c|c|c|c|}
\hline \multirow[t]{2}{*}{ VT (mL) } & \multirow{2}{*}{$\begin{array}{c}\text { Flow-rate } \\
\text { (L/min) }\end{array}$} & \multirow[t]{2}{*}{$\mathrm{f}(/ \mathrm{min})$} & \multirow[t]{2}{*}{$\mathrm{FiO}_{2}$} & \multicolumn{8}{|c|}{$\%$ RAH } \\
\hline & & & & G2S & Portex & $\mathrm{HCH}$ & Pall & G light & G compact & Hygrobac S & Hygroster \\
\hline 200 & 30 & 10 & 0.5 & 94.4 & 95.5 & 95.2 & 95.1 & 94.1 & 94.7 & 96.4 & 94.2 \\
\hline 500 & 30 & 10 & 0.5 & 88.3 & 85.5 & 88.9 & 88.3 & 87.9 & 89.7 & 92.3 & 85.8 \\
\hline 1000 & 30 & 10 & 0.5 & 80.5 & 74.9 & 76.4 & 68.8 & 79.9 & 81.7 & 85.4 & 74.5 \\
\hline 500 & 30 & 5 & 0.5 & 87.8 & 85.6 & 86.3 & 83.6 & 86.4 & 89.0 & 91.0 & 83.4 \\
\hline 500 & 30 & 10 & 0.5 & 88.5 & 85.8 & 87.6 & 84.8 & 87.7 & 90.4 & 92.0 & 85.0 \\
\hline 500 & 30 & 20 & 0.5 & 90.2 & 85.9 & 89.6 & 87.3 & 88.2 & 91.5 & 92.8 & 87.1 \\
\hline 500 & 30 & 10 & 0.5 & 88.0 & 85.9 & 87.4 & 85.0 & 87.8 & 90.3 & 92.2 & 87.1 \\
\hline 500 & 60 & 10 & 0.5 & 89.1 & 87.1 & 89.2 & 87.5 & 88.5 & 91.6 & 92.9 & 90.2 \\
\hline 500 & 90 & 10 & 0.5 & 90.5 & 87.4 & 90.1 & 90.8 & 90.0 & 92.5 & 93.7 & 92.0 \\
\hline
\end{tabular}

Note: $\mathrm{VT}=$ tidal volume; $\mathrm{f}=$ respiratory rate $\mathrm{FiO}_{2}=$ fraction of inspired oxygen; \% RAH = percentage recovery of absolute humidity 
- Hygroscopic

HUMID-VENT 2S (G2S) - Gibeck, Upplands-Väsby,

Sweden

THERMOVENT 1200 (Portex) - SIMS Portex Ltd, Kent,

United Kingdom

Hygroscopic Condenser Humidifier (HCH) - Newmed,

Bromma, Sweden

\section{- Hydrophobic}

BB100MFS (Pall) - Pall, Cornwall, United Kingdom

\section{- Hygroscopic-hydrophobic}

HUMID-VENT FILTER LIGHT (G light) - Gibeck,

Upplands-Väsby, Sweden

HUMID-VENT FILTER COMPACT (G compact) -

Gibeck, Upplands-Väsby, Sweden

HYGROBAC S DAR (Hygrobac S) - Mallinckrodt Medical, Mironda, Italy

HYGROSTER DAR (Hygroster) - Mallinckrodt Medical, Mironda, Italy

The dead-space volumes of each of the tested HMEs were recorded as listed in the manufacturers' specifications.

A thermister/hygrometer (Vaisala, HMI 32, Woburn, MA, USA) was positioned between the HME and the respiratory system analog to continuously measure inspired/expired relative humidity and temperature (Figure 1).

Data were transmitted to a chart recorder (Astro-Med, Inc. Astro-Med Industrial Park, West Warwick, RI, USA) for analysis. Box temperature was continuously monitored using a thermostat (Digitec, model 5810, United Systems Corporation, Dayton, OH, USA) and the hot-air dryer was adjusted to maintain the box temperature at $37^{\circ} \mathrm{C}$. A stabilization period of one hour was allowed for each HME to reach an "efficient" steady state, prior to the actual measurements being recorded. After this time period, we waited for 10 respiratory cycles before measuring $\mathrm{RH}$ and temperature (steady-state values had consistently stabilized by the fourth respiratory cycle).

AH and percentage recovery of absolute humidity (\%RAH) for each HME were determined using the following formulas:

$\mathrm{AH}=$ (relative humidity) $\mathrm{X}$ (content capacity for the given temperature) / 100

$\% \mathrm{RAH}=\left(\mathrm{AH}_{\text {insp }} / \mathrm{AH}_{\text {exp }}\right) \times 100$

Where $\mathrm{AH}_{\text {insp }}$ refers to the absolute humidity of the inspired air and $\mathrm{AH}_{\text {exp }}$ is the equivalent measurement during expiration.

\section{RESULTS}

We initially recorded repeated measurements under different respiratory parameters with different HMEs, and our model showed excellent reproducibility, with a standard deviation for $\mathrm{AH}$ of $0.66 \mathrm{mg} \mathrm{H}_{2} \mathrm{O} / \mathrm{L}$. Our measurements were considered statistically different $(\mathrm{p}<0.05)$ if they differed from one another by more than twice this standard deviation (1.32 $\mathrm{mg} \mathrm{H}_{2} \mathrm{O} / \mathrm{L}$ ) - the so-called $95 \%$ confidence interval. ${ }^{25}$ In this manner, many comparisons were found to be statistically different - their clinical importance is addressed in the Discussion section.

HME models differed slightly in their ability to maintain humidity levels except during high-tidal-volume ventilation, when differences among the HME units were more pronounced. Hygrobac S exhibited a greater \% RAH than the others.

The \% RAH for HME use with the following fixed parameters is shown in Figure 2 and in Table 1: flow rate $=$ $30 \mathrm{~L} / \mathrm{min}, \mathrm{f}=10 / \mathrm{min}, \mathrm{FiO}_{2}=0.5$; when $\mathrm{VT}$ was delivered at 200,500 and $1000 \mathrm{~mL}$.

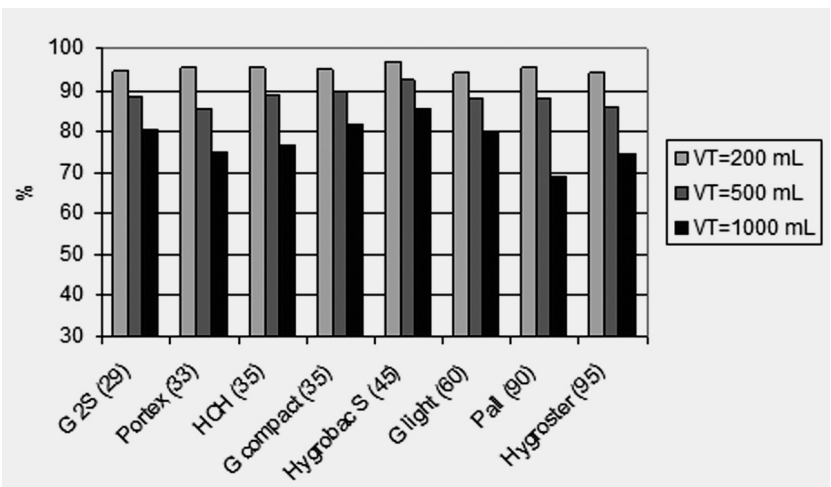

Figure 2 - Effect of tidal volume $(200,500$ and $1000 \mathrm{~mL})$ in the context of $\% \mathrm{RAH}$. The dead-space volume for each HME is shown in parentheses and the HME units are listed in order of increasing dead-space volume. Overall, the HME models differed slightly in terms of their ability to maintain absolute humidity levels, except when a high tidal volume was delivered. There was an inverse relationship between the efficiency of humidification and tidal volume. Hygrobac $\mathrm{S}$ was the HME model with the greatest \% RAH.

We observed that VT affected the ability of a given HME to maintain humidity; when VT increased there was a consistent reduction in \% RAH, which was independent of the HME type (Figure 2, Table 1). At a VT of $200 \mathrm{~mL}$, the $\%$ RAH for each HME was greater than $90 \%$. With the VT set to $500 \mathrm{~mL}$, each HME recovered more than $80 \%$ of $\mathrm{AH}$. However, when the VT was set to $1000 \mathrm{~mL}$, only 3 of the HME units recovered greater than $80 \%$ of $\mathrm{AH}$; and in this scenario the Pall HME model exhibited the lowest \% RAH (under 70\%).

The \% RAH for different respiratory frequencies is displayed in Figure 3 and Table 1. HME models differed 


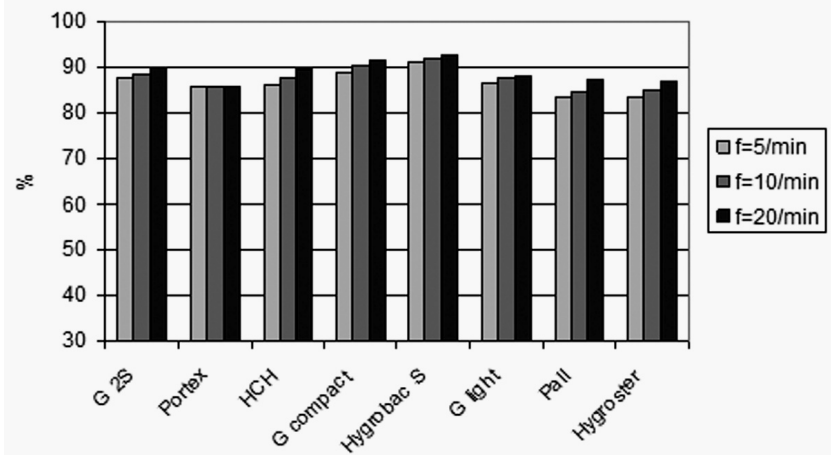

Figure 3 - Effect of respiratory frequency (5, 10 and 20/min) with changing \% RAH. The \%RAH did not depend on frequency. Again, differences in $\%$ RAH between HME were minimal.

slightly in their ability to maintain AH levels but, in general, $\%$ RAH did not change markedly with increasing frequencies given a VT of $500 \mathrm{~mL}$.

The effect of flow rate on \% RAH is displayed in Figure 4 and Table 1 . There were minor differences between HME models and the recovery of AH was not influenced by different flow rates. In our setting of a VT of $500 \mathrm{~mL}$, greater flow rates did not negatively impact the ability of HME to maintain adequate levels of humidity.

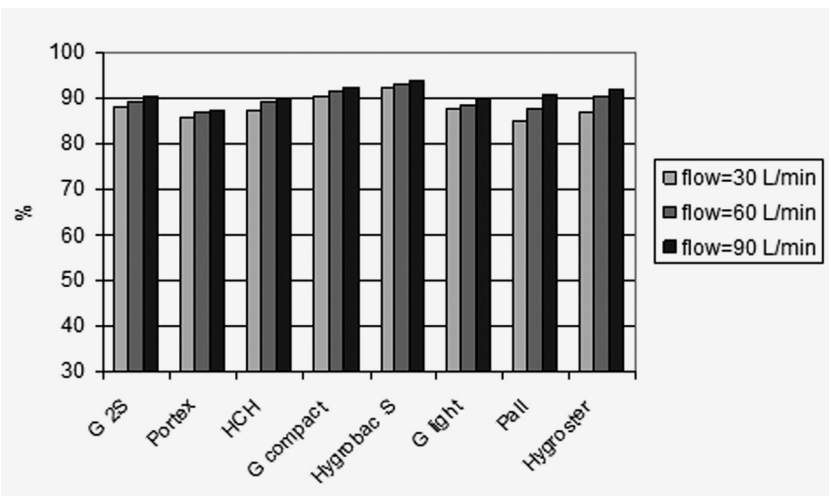

Figure 4 - Effect of flow rates $(30,60$ and $90 \mathrm{~L} / \mathrm{min})$ with changing \%RAH. $\%$ RAH did not depend heavily on flow rates, and we failed to identify any differences between the HME models in terms of humidification efficiency.

\section{DISCUSSION}

Our study assessed the ability of currently available HME units to return heat and humidity to a simulated airway under a variety of ventilatory scenarios. The choice of HME models was based on previous research that focused on models the most commonly found in the largest hospitals of our city.

Previous data show that HME units recover heat and moisture during exhalation and return a significant portion of the heat and humidity during the subsequent inspiration. 14,17,26-29 Our data, however, suggest that the efficiency of this process was not very significantly related to flow and respiratory rates, although it was profoundly affected by increasing VT.

We also failed to identify any significant relationships between the type of HME and \%RAH. HME performance was poorly correlated with the material in each HME, except in cases of high VT. In this particular situation the Pall HME, the only hydrophobic model, had a decreased \%RAH of less than $70 \%$.

These findings are somewhat consistent with the literature. Eckerbom and Lindholm ${ }^{20}$ reported a poor correlation between performance and internal HME volumes (deadspace), although Grolman et al..$^{30}$ found that filter material and size influenced the HME moisture output efficiency.

The efficiency of HME in maintaining heat and humidity has been reported to be affected by the ventilator settings. Our data revealed an inverse relationship between the efficiency of humidification and the tidal volume. ${ }^{18-23}$ For a lower tidal volume of $200 \mathrm{~mL}$, the HME appears to provide adequate humidification. However, the $\mathrm{AH}$ was consistently lower for a VT of $1000 \mathrm{~mL}$ as compared to $500 \mathrm{~mL}$ or 200 $\mathrm{mL}$. Branson and Davis, ${ }^{23}$ Eckerbom and Lindholm ${ }^{20}$ and Wilkes ${ }^{22}$ also observed that HMEs delivered higher humidity when the VT was $500 \mathrm{~mL}$ as compared with $1000 \mathrm{~mL}$ in their lung model studies. We found that the most efficient HME was the Hygrobac S at all VT settings.

In our study, \% RAH was nearly constant when we changed the respiratory rate and flow rate for each HME. Other studies have suggested that increasing minute ventilation decreases the efficiency of humidification by an HME., ${ }^{9,23}$ When we compared different frequencies, the efficiency of humidification remained nearly constant. The efficiency of humidification decreased when high minute ventilation was achieved by increasing the tidal volume. Our data suggest that the previously described minute ventilation effect on HME efficiency is due almost exclusively to the role played by VT.

When we changed the flow rate, we failed to observe changes in the humidification efficiency. Other studies ${ }^{18,24}$ found that flow rate was a performance-changing factor with higher gas flow-rates decreasing the efficiency of humidification recovery as provided by the HME. It is likely that singularities in the respiratory models between these studies and ours may account for the observed differences.

One limitation of our study is the fact that we collected our data in a respiratory system analog. Although we tried to control all possible pertinent variables, to directly translate our findings into the clinical scenario would be an oversimplification. Further studies at the ICU will probably help corroborate these data and evaluate their relevance in a clinical scenario. 
ICU patients are a heterogeneous group and many patients receive positive pressure ventilation through oral or nasal endotracheal intubation or via tracheotomy. In spite of the trend towards a protective strategy that involves low tidal volumes, ${ }^{31}$ some patients require high-tidal-volume ventilation. Our data suggest that the use of $\mathrm{HH}$ instead of HME should be considered for this subset of patients, in order to avoid the possibility of insufficient humidification and all potential associated complications. ${ }^{8-11}$

Our data also indicate that the role of flow and respiratory rate is of lesser importance; accordingly, adjustments to these parameters seem to exert only a small impact on the final HME performance.

\section{CONCLUSIONS}

HME are more efficient when used with low-VT ventilation. The roles of flow and respiratory rate were of lesser importance, suggesting that their adjustment has a less significant effect on HME performance.

\section{REFERENCES}

1. Chiumello D, Pelosi P, Candiani A, Bottino N, Aspesi M, Severgnini P, et al. The conditioning of the gases in mechanically ventilated patients. Pneumon. 2002;15:61-8.

2. Branson RD. Humidification for patients with artificial airways. Respir Care. 1999; 44:630-41

3. AARC clinical practice guideline. Humidification during mechanical ventilation. American Association for Respiratory Care. Respir Care. 1992;37:887-90.

4. Branson RD, Davis K, Jr, Campbell RS, Johnson DJ, Porembka DT. Humidification in the intensive care unit. Prospective study of a new protocol utilizing heated humidification and a hygroscopic condenser humidifier. Chest. 1993;104:1800-5

5. Iotti GA, Olivei MC, Palo A, Galbusera C, Veronesi R, Comelli A, et al. Unfavorable mechanical effects of heat and moisture exchangers in ventilated patients. Intensive Care Med. 1997;23:399-405.

6. Rathgeber J. Devices used to humidify respired gases. Respir Care Clin N Am. 2006; 12:165-82.

7. Ricard JD, Markowicz P, Djedaini K, Mier L, Coste F, Dreyfuss D. Bedside evaluation of efficient airway humidification during mechanical ventilation of the critically ill. Chest. 1999;115:1646-52.

8. Roustan JP, Kienlen J, Aubas P, Aubas S, du Cailar J. Comparison of hydrophobic heat and moisture exchangers with heated humidifier during prolonged mechanical ventilation. Intensive Care Med. 1992;18:97100.

9. Cohen IL, Weinberg PF, Fein IA, Rowinski GS. Endotracheal tube occlusion associated with the use of heat and moisture exchangers in the intensive care unit. Crit Care Med. 1988;16:277-9.

10. Villafane MC, Cinnella G, Lofaso F, Isabey D, Harf A, Lemaire F, et al. Gradual reduction of endotracheal tube diameter during mechanical ventilation via different humidification devices. Anesthesiology. $1996 ; 85: 1341-9$

11. Martin C, Perrin G, Gevaudan MJ, Saux P, Gouin F. Heat and moisture exchangers and vaporizing humidifiers in the intensive care unit. Chest. 1990;97:144-9.

12. Ricard JD, Le Miere E, Markowicz P, Lasry S, Saumon G, Djedaini K, et al. Efficiency and safety of mechanical ventilation with a heat and moisture exchanger changed only once a week. Am J Respir Crit Care Med. 2000;161:104-9.
13. Lucato JJJ, Tucci MR, Schettino GPP, Adams AB, Fu C, Forti Jr G, et al Evaluation of resistance in eight different heat and moisture exchangers: effects of saturation and flow rate/profile. Respir Care. 2005; 50:63643.

14. Hess DR, Branson RD. Humidification. In: Branson RD, Hess DR, Chatburn RL, editors. Respiratory care equipment. 2a ed. ed. Philadelphia: Lippincott Williams \& Wilkins; 1999. p.101-32.

15. Jackson C, Webb AR. An evaluation of the heat and moisture exchange performance of four ventilator circuit filters. Intensive Care Med. 1992;18:264-8

16. Shelly MP. The humidification and filtration functions of the airways. Respir Care Clin N Am. 2006;12:139-48.

17. Hurni JM, Feihl F, Lazor R, Leuenberger P, Perret C. Safety of combined heat and moisture exchanger filters in long-term mechanical ventilation. Chest. 1997;111:686-91.

18. Unal N, Kanhai JK, Buijk SL, Pompe JC, Holland WP, Gultuna I, et al. A novel method of evaluation of three heat-moisture exchangers in six different ventilator settings. Intensive Care Med. 1998;24:138-46.

19. Ogino M, Kopotic R, Mannino FL. Moisture-conserving efficiency of condenser humidifiers. Anaesthesia. 1985;40:990-5.

20. Eckerbom B, Lindholm CE. Performance evaluation of six heat and moisture exchangers according to the Draft International Standard (ISO/ DIS 9360). Acta Anaesthesiol Scand. 1990;34:404-9.

21. Hay R, Miller WC. Efficacy of a new hygroscopic condenser humidifier. Crit Care Med. 1982;10:49-51.

22. Wilkes AR. The moisture-conserving performance of breathing system filters during the first three minutes of simulated use. Anaesthesia. 2004;59:265-70.

23. Branson RD, Davis K, Jr. Evaluation of 21 passive humidifiers according to the ISO 9360 standard: moisture output, dead space, and flow resistance. Respir Care. 1996; 41:736-43.

24. Chalon J, Markham JP, Ali MM, Ramanathan S, Turndorf H. The pal ultipor breathing circuit filter--an efficient heat and moisture exchanger. Anesth Analg. 1984; 63:566-70.

25. Bland JM, Altman DG. Measurement error. Bmj. 1996; 313:744. 
26. Holt TO. Aerosol generators and humidifiers. In: Barnes TA, editor Core textbook of respiratory care practice. 2a ed. ed. St. Louis: Mosby; 1994. p. 441-84.

27. Thomachot L, Viviand X, Boyadjiev I, Vialet R, Martin C. The combination of a heat and moisture exchanger and a Booster: a clinical and bacteriological evaluation over $96 \mathrm{~h}$. Intensive Care Med. 2002;28:147-53.

28. Conti G, De Blasi RA, Rocco M, Pelaia P, Antonelli M, Bufi M, et al. Effects of the heat-moisture exchangers on dynamic hyperinflation of mechanically ventilated COPD patients. Intensive Care Med. 1990;16:441-3.
29. Mebius C. A comparative evaluation of disposable humidifiers. Acta Anaesthesiol Scand. 1983;27:403-9.

30. Grolman W, Blom ED, Branson RD, Schouwenburg PF, Hamaker RC. An efficiency comparison of four heat and moisture exchangers used in the laryngectomized patient. Laryngoscope. 1997;107:814-20.

31. Amato MB, Barbas CS, Medeiros DM, Magaldi RB, Schettino GP, Lorenzi-Filho G, et al. Effect of a protective-ventilation strategy on mortality in the acute respiratory distress syndrome. N Engl J Med. $1998 ; 338: 347-54$ 